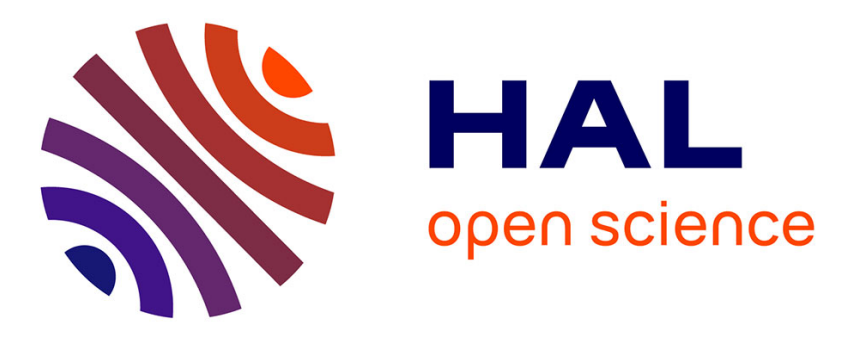

\title{
Copper Complexes as Bioinspired Models for Lytic Polysaccharide Monooxygenases
}

\author{
Alda Lisa Concia, Maria Rosa Beccia, Maylis Orio, Francine Terra Ferre, \\ Marciela Scarpellini, Frédéric Biaso, Bruno Guigliarelli, Marius Réglier, A. \\ Jalila Simaan
}

\section{To cite this version:}

Alda Lisa Concia, Maria Rosa Beccia, Maylis Orio, Francine Terra Ferre, Marciela Scarpellini, et al.. Copper Complexes as Bioinspired Models for Lytic Polysaccharide Monooxygenases. Inorganic Chemistry, 2017, 56 (3), pp.1023 - 1026. 10.1021/acs.inorgchem.6b02165 . hal-01440965

\section{HAL Id: hal-01440965 https://hal-amu.archives-ouvertes.fr/hal-01440965}

Submitted on 2 Feb 2022

HAL is a multi-disciplinary open access archive for the deposit and dissemination of scientific research documents, whether they are published or not. The documents may come from teaching and research institutions in France or abroad, or from public or private research centers.
L'archive ouverte pluridisciplinaire HAL, est destinée au dépôt et à la diffusion de documents scientifiques de niveau recherche, publiés ou non, émanant des établissements d'enseignement et de recherche français ou étrangers, des laboratoires publics ou privés. 


\begin{abstract}
We report here two copper complexes as first functional models for Lytic Polysaccharide Monooxygenases, mononuclear copper-containing enzymes involved in recalcitrant polysaccharide breakdown. These complexes feature similar structural and spectroscopic properties to that of the enzyme. In addition, they catalyze the oxidative cleavage of the model substrate $p$-nitrophenyl- $\beta$-dglucopyranoside. More importantly, a particularly stable $\mathrm{Cu}(\mathrm{II})$-hydroperoxide intermediate is detected in the reaction conditions.
\end{abstract}

Much attention has been recently directed to Lytic Polysaccharide Monooxygenases (LPMOs) for their boosting activity during enzymatic conversion of biomass recalcitrant polysaccharides (cellulose, chitin etc) via an oxidative cleavage mechanism. ${ }^{1}$ LPMOs are copper-containing monooxygenases catalyzing the oxidation of glycosidic bonds creating new polymer chain breaks, which facilitates the action of classical glycoside hydrolases. Dioxygen activation at the copper site in the presence electron donors (ascorbate, proteic partner, etc) leads to the hydroxylation of an inert $\mathrm{C}-\mathrm{H}$ bond at the glycosidic linkage (Figure 1). This glycosidic bond is further cleaved off upon elimination of a water molecule. Hydroxylation at position $\mathrm{C}_{1}$ is preferred but LPMOs performing the oxidative cleavage of cellulose at position $\mathrm{C}_{4}$ has also been reported., ${ }^{1,2}$ LPMOs harbor a solvent exposed mononuclear copper active site at the center of a flat surface that interacts with the polysaccharide substrate. 3 The active site copper ion is coordinated by two histidine residues, including the $N$-terminal histidine that is bound both by the side chain imidazole and the main-chain amino group ('Histidine-brace motif). A tyrosine or a phenylalanine residue is located in axial position (Figure 1). ${ }^{1}$ Finally, the imidazole moiety of the $N$-terminal histidine is $N$-methylated in fungal LPMOs.

A
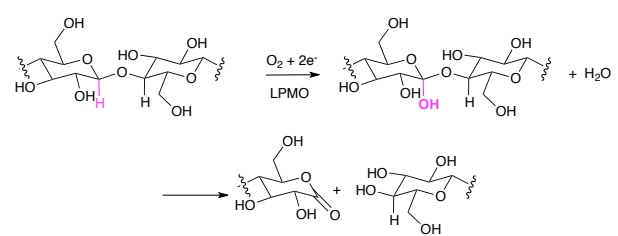

B

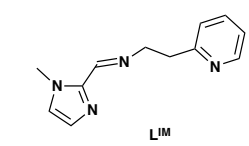

C
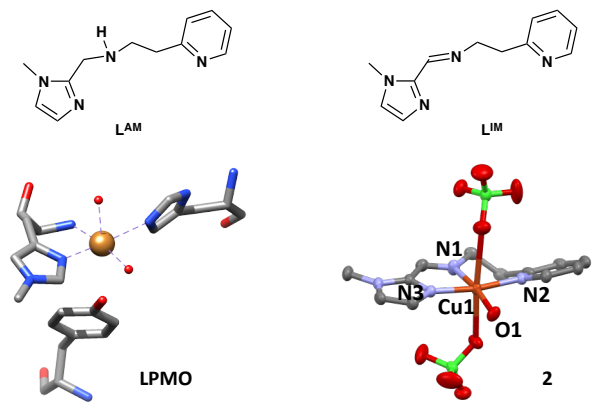

Figure 1. A) Oxidative cleavage of polysaccharides catalyzed by LPMO. B) Ligands used in the present study. C) Active site of LPMO from Thermoascus auriantacus (pdb 2yet) and ORTEP diagram of complex 2 (30\% thermal ellipsoid plots). Hydrogen atoms were omitted for clarity. Selected distances in Å: Cu1-N1: 2.000(2), Cu1-N2: 2.001(2), Cu1-N3: 1.973(2), Cu1-O1: 1.9771(19).

LPMOs are members of the mononuclear copper containing monooxygenases in which reactive copper-oxygen species are involved in $\mathrm{C}-\mathrm{H}$ bond hydroxylation. 4 In the case of LPMOs, the nature of the copper-oxygen intermediates involved in $\mathrm{C}-\mathrm{H}$ bond activation is still debated. 5 Several copperoxygen intermediates have been characterized using biomimetic complexes, ${ }^{6}$ and much can be learnt on LPMOs mechanism by using a small model approach. Recently, a Cu(II) complex based on bis(benzimidazole)amine ligand was prepared as structural model for LPMOs but no oxidative reactivity was reported. 7 We have prepared two ligands 
(L ${ }^{\mathrm{AM}}$ and $\mathrm{L}^{\mathrm{IM}}$ ) providing a $N_{3}$-coordination sphere for a copper ion and featuring $N$-methylated imidazole moiety (Figure 1). ${ }^{8}$ The corresponding complexes $\left[\left(\mathrm{L}^{\mathrm{AM}}\right) \mathrm{Cu}\left(\mathrm{CH}_{3} \mathrm{CN}\right)\right]\left(\mathrm{ClO}_{4}\right)_{2}$ (1) and $\left[\left(\mathrm{L}^{\mathrm{IM}}\right) \mathrm{Cu}\left(\mathrm{OH}_{2}\right)\right]\left(\mathrm{ClO}_{4}\right)_{2} \cdot \mathrm{H}_{2} \mathrm{O}(\mathbf{2})$ were prepared. $\mathrm{X}$ ray diffraction analysis have shown that, in both cases, the $\mathrm{Cu}$ (II) ions are in pseudo-octahedral geometries and are coordinated in the equatorial plane by the 3 nitrogen donors from the ligands (Figure 1 and $\mathrm{SI}$ ). The $\mathrm{Cu}-\mathrm{N}$ distances are found ranging from ca. 1.97 to $2.03 \AA$ and are within the range of distances found in similar complexes ${ }^{8}$ as well as in the enzymatic systems. ${ }^{1,3}$ The Electron Paramagnetic Resonance (EPR) spectra of the complexes were recorded in aqueous solution (SI). The EPR parameters obtained from simulation with axial set of parameters are the following $\mathrm{g}_{/ /=}=$ 2.260, $\left|\mathrm{A}_{/ /}\right|=530 \mathrm{MHz}, \mathrm{g}_{+}=2.059$ for $\mathbf{1}$ and $\mathrm{g}_{/ /}=$ 2.265, $\left|\mathrm{A}_{/} /\right|=530 \mathrm{MHz}, \mathrm{g}_{+}=2.060$ for $\mathbf{2}$. These parameters are in good agreement with those obtained for LPMOs. ${ }^{1,3,9}$ The redox potentials for the $\mathrm{Cu}(\mathrm{II}) / \mathrm{Cu}(\mathrm{I})$ couples in $\mathbf{1}$ and $\mathbf{2}$ were measured by cyclic voltammetry and redox titration. These potentials are found ranging from 5-50 $\mathrm{mV} v$ s. SHE depending on the method used and on the conditions (SI). These potential are much lower than those observed for the enzymatic systems, which range from $150-370 \mathrm{mV} .{ }^{1,9}$

\section{Scheme 1. Oxidative cleavage of $p$ - nitrophenyl- $\beta$-D-glucopyranoside}

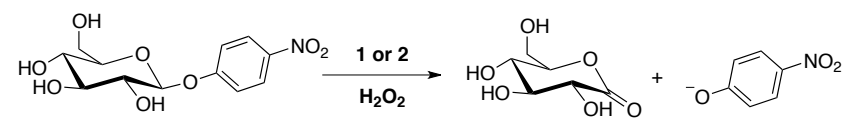

The LPMO-like reactivity of the complexes was evaluated in the presence of hydrogen peroxide and $p$-nitrophenyl- $\beta$-D-glucopyranoside was used as a model substrate (Scheme 1). The formation of $p$ nitrophenolate was monitored under various conditions by spectrophotometry $\left(\lambda_{\max }=400 \mathrm{~nm}, \varepsilon=\right.$ $\left.18500 \mathrm{~mol}^{-1} \mathrm{Lcm}^{-1}\right) .{ }^{10}$ The initial velocities were found dependent on the concentrations of complexes and are up to 6-times higher than that obtained in the presence of a copper salt (Figure 2). The reaction rates were also dependent on hydrogen peroxide or substrate concentration (SI). Consequently, after 10 minutes of reaction, a 6-fold improvement in oxidation yield is obtained in the presence of the complexes as compared to $\mathrm{CuSO}_{4}$ (o.1 mM of catalyst, see SI). After longer reaction times ( $24 \mathrm{~h}$ ), up to $500 \mu \mathrm{M}$ of $p$-nitrophenolate are produced using $10 \mu \mathrm{M}$ of complexes (50 TON). In absence of either hydrogen peroxide or complex, low amount of $p$-nitrophenolate is detected (30-50 $\mu \mathrm{M})$ suggesting that oxidative processes are involved rather than hydrolysis. In addition, gluconic acid (arising from gluconolactone) was evidenced by chromatographic analysis and ESI-MS analysis in the reaction mixtures ( 1 or $\left.\mathbf{2}+\mathrm{H}_{2} \mathrm{O} 2\right)$ after 24 hours, thus strongly supporting oxidative cleavage similar to that catalyzed by LPMO (SI). Stepwise addition of hydrogen peroxide ( $15 \mathrm{mM}$ every $2 \mathrm{~h}, 5$ additions) increases the reaction yield and $2.5 \mathrm{mM}$ of $p$-nitrophenolate are detected after $24 \mathrm{~h}$ (using $50 \mu \mathrm{M}$ of catalyst). Each addition is followed by the generation of $c a .300 \mu \mathrm{M}$ of $p$-nitrophenolate $(6$ TON) indicating that the reactive species can be regenerated by consecutive addition of hydrogen peroxide.

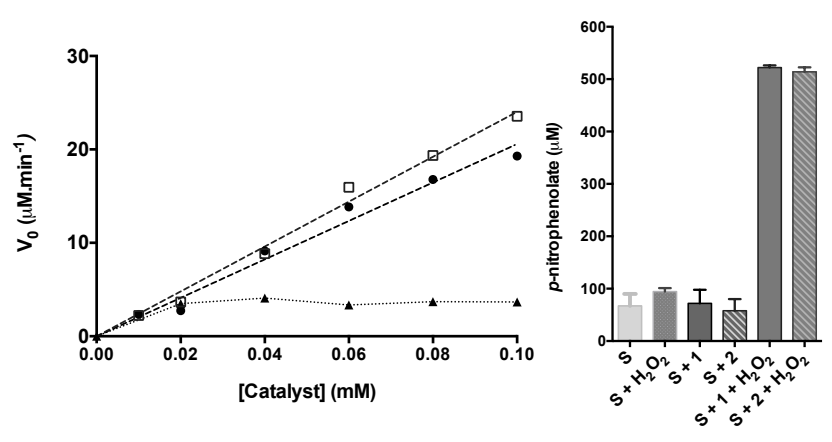

Figure 2. Reaction of $p$-nitrophenyl- $\beta$-D-glucopyranoside (S) with complexes 1 and 2 and $\mathrm{H}_{2} \mathrm{O}_{2}$ in carbonate buffer $100 \mathrm{mM} \mathrm{pH} 10.5$ and at $30^{\circ} \mathrm{C}$ with $\left[\mathrm{H}_{2} \mathrm{O}_{2}\right]=20 \mathrm{mM}$ and $[\mathrm{S}]=20 \mathrm{mM}$. Left: initial velocities as a function of complex concentration for complexes $1(\bullet)$ and $2(\square)$ and for $\mathrm{CuSO}_{4}(\mathbf{\Delta})$ Right: concentration of $p$-nitrophenolate obtained after 24 hours of reaction with $[\mathbf{1}$ or $\mathbf{2}]=0.01 \mathrm{mM}$.

Finally, the addition of $\mathrm{H}_{2} \mathrm{O}_{2}$ (in buffers) or $\mathrm{H}_{2} \mathrm{O}_{2} / \mathrm{Et}_{3} \mathrm{~N}$ (in water) on solutions of $\mathbf{1}$ or $\mathbf{2}$ is followed by changes in the UV-visible spectra and intense absorption bands centered at $305 \mathrm{~nm}$ with shoulders around $375 \mathrm{~nm}$ appear for both complexes (Figure 3). These species are stable from minutes to several hours depending on the conditions (concentrations, $\mathrm{pH}$ ) and then slowly decay. The intermediates still display d-d transitions around 650 $\mathrm{nm}$ which suggests the maintenance of $\mathrm{Cu}(\mathrm{II})$ redox state. In the literature, addition of $\mathrm{H}_{2} \mathrm{O}_{2}$ in the presence of $\mathrm{Et}_{3} \mathrm{~N}$ on different copper complexes in organic solvents and at low temperature has led to the identification of several $\mathrm{CuOOH}$ intermediates displaying charge-transfer transitions in the 350$400 \mathrm{~nm}$ region. ${ }^{5}$ Yet, there are only few data on copper-oxygen intermediates formed in aqueous solutions and to the best of our knowledge only few bridged-peroxo intermediates have been observed. ${ }^{11}$ In the present case, no significant decrease of EPR intensities is observed in different conditions and the intermediates display similar EPR spectra than the parent complexes (SI). It is therefore possible that the copper coordination sites of $\mathbf{1}$ or $\mathbf{2}$ are substituted with hydroperoxide ligand without altering significantly the copper coordination geometry, as already observed for some $\mathrm{CuOOH}$ species. ${ }^{12}$ Correlation between formation/decay of the intermediates and production of $p$-nitrophenolate was unfortunately difficult due 
to spectrophotometric overlap between the substrate and the intermediate (SI).

Density Functional Theory (DFT) calculations were undertaken to get deeper insight into the structure of the intermediate. The starting complex was subjected to geometry optimization and different structures were considered including replacement of acetonitrile by a water ligand (SI) and provided pentacoordinated copper centers (one perchlorate was decoordinated). The structure of $\mathbf{1}^{*}$ $\left(\left[\mathrm{L}^{\mathrm{AM}} \mathrm{Cu}\left(\mathrm{OH}_{2}\right)\left(\mathrm{ClO}_{4}\right)\right]^{+}\right)$was used as starting point to compute structures of the intermediate. Different mononuclear intermediates displaying peroxo and hydroperoxo ligands were considered (SI) and TDDFT calculations were carried out on their optimized structures to get insight into their optical properties. Comparison between the predicted and experimental spectra indicated that the best model consists in one hydroperoxo and one water bound to the copper, namely $\mathbf{1}^{*}-\mathbf{O O H}(\mathrm{SI})$. The calculations reproduce the experimental spectra of the initial complex and of the intermediate and in particular a ligand-to-metal CT in $\mathbf{1}^{*}$ and a peroxo-tometal CT in $\mathbf{1}^{*}$-OOH calculated at 278 and $331 \mathrm{~nm}$ respectively, that are found at 265 and $305 \mathrm{~nm}$ experimentally (the shift is also well reproduced). Finally, computed electronic structure and magnetic properties show that $\mathbf{1}^{*}$ and $\mathbf{1}^{*}-\mathbf{O O H}$ display singly occupied molecular orbitals (SOMOs) with dominant $\mathrm{Cu} 3 \mathrm{~d}_{\mathrm{x}^{2}-\mathrm{y}}{ }^{2}$ character, in agreement with the computed and experimental EPR parameters (SI).

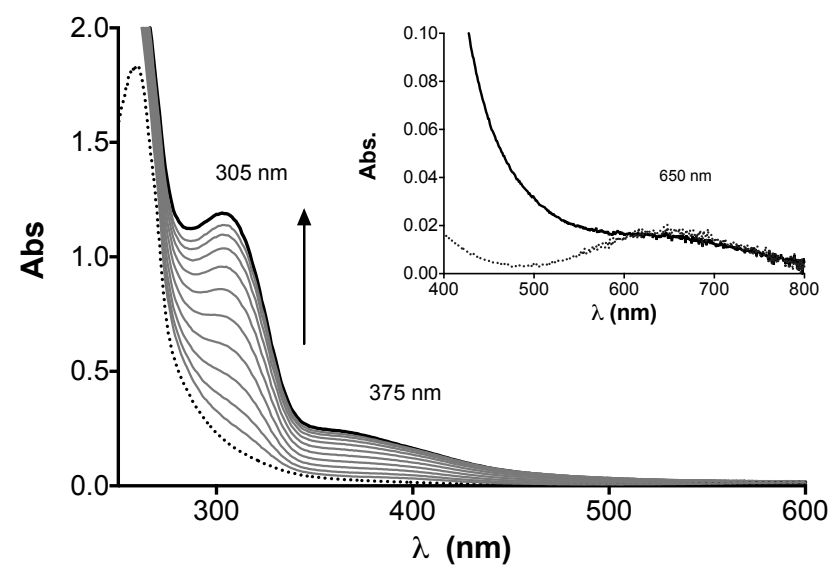

Figure 3. Absorption spectra of $\mathbf{1}$ at $0.25 \mathrm{mM}$ in aqueous solution (----) upon addition of $25 \mathrm{mM}$ of hydrogen peroxide at room temperature. Formation of an intermediate (-) over 15 minutes reaction time. Inset: zoom around the d$\mathrm{d}$ transitions region.

Some $\mathrm{CuOOH}$ intermediates were shown to display oxidative activities. ${ }^{13}$ However, it was also suggested that high-valent copper-oxo species or radicals derived from hydroperoxo intermediates could be responsible for the observed reactivities. ${ }^{14}$ Therefore the role of $\mathrm{CuOOH}$ species in the reactiv- ity of complexes $\mathbf{1}$ and $\mathbf{2}$ remains to be elucidated. $\$$ Interestingly, copper complexes were recently shown to efficiently perform alkane oxidation in the presence of $\mathrm{H}_{2} \mathrm{O} 2$ through Fenton-like mechanisms. ${ }^{15}$ Although plausible with model complexes, Fenton mechanism would not be expected for the selective oxidations ( $\mathrm{C}_{1}$ or $\mathrm{C}_{4}$ ) performed by LPMO enzymes. This work however sheds light on species that should be considered in discussions of mechanism of mononuclear copper-containing systems.

\section{ASSOCIATED CONTENT}

Supporting Information containing experimental, crystallographic, EPR, redox and calculation data is available free of charge on the ACS Publications website.

\section{AUTHOR INFORMATION}

\section{Corresponding Author}

jalila.simaan@univ-amu.fr; Phone: +33 491289151

\section{Funding Sources}

This work has been financially supported by A*MIDEX (FUNCOPPER, ANR-11-IDEX-OOO1-02).

\section{Notes}

§Dimethylpyrroline N-oxide (DMPO) was used as radical trapping agent. Similar quantities of DMPO$\mathrm{OH}$ radicals were detected by $\mathrm{EPR}$ in the reaction conditions, in presence or in absence of complexes, rendering any conclusion difficult here.

\section{ACKNOWLEDGMENT}

Dr. Jean-Guy Berrin and Dr. Bernard Henrissat are acknowledged for fruitful discussions. The authors are grateful to national EPR network RENARD (IR CNRS 3443) and Aix-Marseille University EPR center. Coordenação de Aperfeiçoamento de Pessoal de Nível Superior (CAPES) is also acknowledged.

\section{REFERENCES}

(1) a) Vaaje-Kolstad, G.; Westereng, B.; Horn, S. J.; Liu, Z.; Zhai, H.; Sørlie, M.; Eijsink, V. G. H. An Oxidative Enzyme Boosting the Enzymatic Conversion of Recalcitrant Polysaccharides. Science 2010, 330, 219-222 b) Beeson, W. T.; Vu, V. V.; Span, E. A.; Phillips, C. M.; Marletta, M. A. Cellulose Degradation by Polysaccharide Monooxygenases. Annu. Rev. Biochem. 2015, 84, 923-946 c) Hemsworth, G. R.; Johnston, E. M.; Davies, G. J.; Walton, P. H. Lytic Polysaccharide Monooxygenases in Biomass Conversion. Trends Biotechnol 2015, 33, 747761.

(2) a) Vu, V. V.; Beeson, W. T.; Phillips, C. M.; Cate, J. H. D., Marletta M. A.; Determinants of Regioselective Hydroxylation in the Fungal Polysaccharide Monooxygenases. J. Am. Chem. Soc. 2014, 136, 562-565 b) Bennati-Granier, C.; Garajova, S.; Champion, C.; Grisel, S.; Haon, M.; Zhou, S.; Fanuel, M.; Ropartz, D.; Rogniaux, H.; Gimbert, I.; Record, E.; Berrin, J.-G.; Substrate specificity and regioselectivity of fungal AA9 lytic polysaccharide monooxygenases secreted by Podospora anserina. Biotechnol Biofuels, 2015, 8, 90. 
(3) Frandsen, K. E. H.; Simmons, T. J.; Dupree, P.; Poulsen, J.-C. N.; Hemsworth, G. R.; Ciano, L.; Johnston, E. M.; Tovborg, M.; Johansen, K. S.; Freiesleben, von, P.; Marmuse, L.; Fort, S. E. B.; Cottaz, S.; Driguez, H.; Henrissat, B.; Lenfant, N.; Tuna, F.; Baldansuren, A.; Davies, G. J.; Leggio, Lo, L.; Walton, P. H. The molecular basis of polysaccharide cleavage by lytic polysaccharide monooxygenases. Nat. Chem. Biol, 2016, 12, 298-303.

(4) a) Copper Mononuclear Monooxygenases. Réglier, M.; Belle, D. C. In Encyclopedia of Metalloproteins; Springer New York: New York, NY, 2013; pp 723-729 b) Liu, J. J.; Diaz, D. E.; Quist, D. A.; Karlin, K. D.; Copper(I)-Dioxygen Adducts and Copper Enzyme Mechanisms, Isr. J. Chem. 2016, 56, 738755

(5) a) Walton, P. H.; Davies, G. J. On the catalytic mechanisms of lytic polysaccharide monooxygenases. Curr. Opin. Chem. Biol. 2016, 31, 195-207. b) Span, E. A.; Marletta, M. A. The framework of polysaccharide monooxygenase structure and chemistry . Curr. Opin. Struct. Biol. 2015, 35, 93-99.

(6) a) Gagnon, N.; Tolman, W. B. [CuO $]^{+}$and $[\mathrm{CuOH}]^{2+}$ Complexes: Intermediates in Oxidation Catalysis? Acc. Chem. Res. 2015, 48, 2126-2131 b) Itoh, S. Developing Mononuclear Copper-Active-Oxygen Complexes Relevant to Reactive Intermediates of Biological Oxidation Reactions Acc. Chem. Res. 2015, 48, 2066-2074.

(7) Castillo, I.; Neira, A. C.; Nordlander, E.; Zeglio, E. Bis(benzimidazolyl)amine copper complexes with a synthetic 'histidine brace' structural motif relevant to polysaccharide monooxygenases. Inorg Chim Acta 2014, 422, 152-157.

(8) a) Drew, M. G. B.; Das, D.; De, S.; Datta, D. Effect of $\mathrm{H}$-bonding on the ambivalence of SCN towards copper(II). Inorg Chim Acta 2009, 362, 1501-1505 b) Kumar, P.; Gorai, S.; Kumar Santra, M.; Mondal, B.; Manna, D. DNA binding, nuclease activity and cytotoxicity studies of $\mathrm{Cu}(\mathrm{II})$ complexes of tridentate ligands. Dalton Trans. 2012, 41, 7573-7579.

(9) Garajova, S.; Mathieu, Y.; Beccia, M. R.; BennatiGranier, C.; Biaso, F.; Fanuel, M.; Ropartz, D.; Guigliarelli, B.;
Record, E.; Rogniaux, H.; Henrissat, B.; Berrin, J.-G. Singledomain avoenzymes trigger lytic polysaccharide monooxygenases for oxidative degradation of cellulose. Sci. Rep. 2016, 6, 28276 .

(10) Selmeczi, K.; Giorgi, M.; Speier, G.; Farkas, E.; Réglier, M. Mono- versus Binuclear Copper(II) Complexes in Phosphodiester Hydrolysis Eur. J. Inorg. Chem. 2006, 5, 1022-1031.

(11) Zhu, Q.; Lian, Y.; Thyagarajan, S.; Rokita, S. E.; Karlin, K. D.; Blough, N. V. Hydrogen Peroxide and Dioxygen Activation by Dinuclear Copper Complexes in Aqueous Solution: Hydroxyl Radical Production Initiated by Internal Electron Transfer. J. Am. Chem. Soc. 2oo8, 130, 6304-6305.

(12) Ohtsu, H.; Itoh, S.; Nagatomo, S.; Kitagawa, T.; Ogo, S.; Watanabe, Y.; Fukuzumi, S. Characterization of ImidazolateBridged Dinuclear and Mononuclear Hydroperoxo Complexes. Inorg. Chem. 2001, 40, 3200-3207.

(13) Fujii, T.; Naito, A.; Yamaguchi, S.; Wada, A.; Funahashi, Y.; Jitsukawa, K.; Nagatomo, S.; Kitagawa, T.; Masu$\mathrm{da}, \mathrm{H}$. Construction of a square-planar hydroperoxo-copper(II) complex inducing a higher catalytic reactivity. Chem. Commun. 2003, 21, 2700-2702

(14) a) Maiti, D.; Narducci Sarjeant, A. A.; Karlin, K. D. Copper-Hydroperoxo-Mediated N-Debenzylation Chemistry Mimicking Aspects of Copper Monooxygenases. Inorg. Chem. 2008, 47, 8736-8747 b) Kim, S.; Ginsbach, J. W.; Lee, J. Y.; Peterson, R. L.; Liu, J. J.; Siegler, M. A.; Sarjeant, A. A.; Solomon, E. I.; Karlin, K. D.; Amine Oxidative N-Dealkylation via Cupric Hydroperoxide Cu-OOH Homolytic Cleavage Followed by Site-Specific Fenton Chemistry. J. Am. Chem. Soc. 2015, 137, 2867-2874.

(15) Garcia-Bosch, I.; Siegler, M. A.; Copper-Catalyzed Oxidation of Alkanes with $\mathrm{H} 2 \mathrm{O} 2$ under a Fenton-like Regime. Angew. Chem. Int. Ed. 2016, 55, 12873 -12876. 


\section{For Table of Contents Only:}

Two copper(II) complexes are described as models for the Lytic Polysaccharide Monooxygenases, coppercontaining enzymes involved in oxidative cleavage of recalcitrant polysaccharides. These complexes are able to catalyze the oxidative cleavage of a model substrate, $p$-nitrophenyl- $\beta$-d-glucopyranoside, in the presence of hydrogen peroxide. An possible $\mathrm{CuOOH}$ intermediate is detected in the reaction conditions.

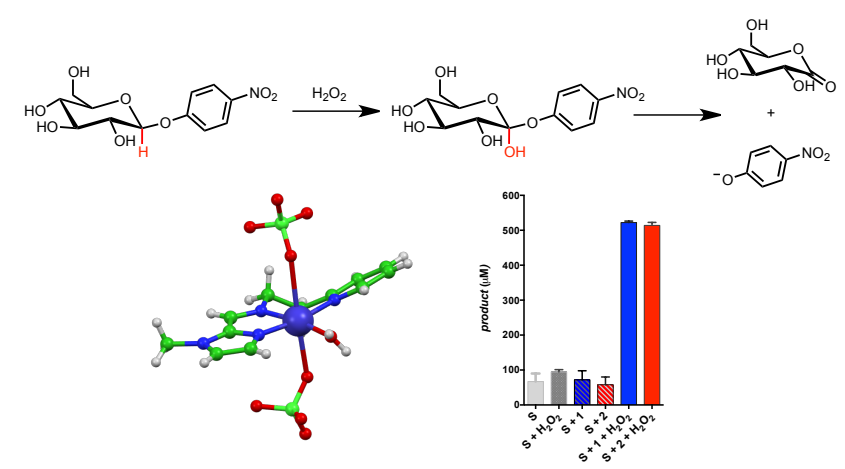

